\title{
The Regeneration of a Hormone-Sensitive Muscle (Levator Ani) in the Rat
}

\author{
Ernest Gutmann and Bruce M. Carlson ${ }^{1}$ \\ Institute of Physiology, Czechoslovak Acadeny of Sciences, Praha 4, KRC, \\ Ciechoslovakia, and Department of Anatomy, University of Michigan, \\ Ann Arbor, Michigan 48109
}

Received September 6, 1977

In 1-month-old male rats the levator ani muscle was crushed and allowed to regenerate. The main questions were whether or not the course of regeneration is similar to that of limb muscles and whether or not the regenerating levator ani muscle is sensitive to the effects of testosterone. Regeneration was followed in three groups of rats: castrated, normal, and testosterone-treated. Histological analysis revealed no detectable differences between regeneration of the levator ani and other muscies. By 31 days both the gross weight and mean cross-sectional area of the muscle fibers in castrated rats were much less than in the other two groups. Testosterone-treated muscles were larger, but not significantly so, than normal regenerating muscles. Twitch and tetanic tensions were lowest in regenerating muscles from castrated rats and highest in those from hormone-treated rats. Both the contraction (time to peak) and half-relaxation times at 7 and 14 days were fastest in hormone-treated muscles and were very slow in castrated rats. By 30 days, the differences between normal and hormone-treated muscles had disappeared. It is concluded that the regenerating levator ani muscle is sensitive to the effects of testosterone.

\section{INTRODUCTION}

The levator ani muscle in the rat (Fig. 1A) is one of a group of vertebrate muscles (other examples being the temporalis muscle in guinea pigs and the intrinsic thumb muscles of frogs) that shows a pronounced responsiveness to the effects of testosterone. Present in both sexes at birth,

${ }^{1}$ Supported in part by grants from the Muscular Dystrophy Association and the National Institutes of Health. This work was made possible by a scientific exchange sponsored by the Czechoslovak and U. S. Academies of Sciences. Dr. Gutmann was deceased August 6,1977. Direct reprint requests to Dr. Carlson at the University of Michigan. 


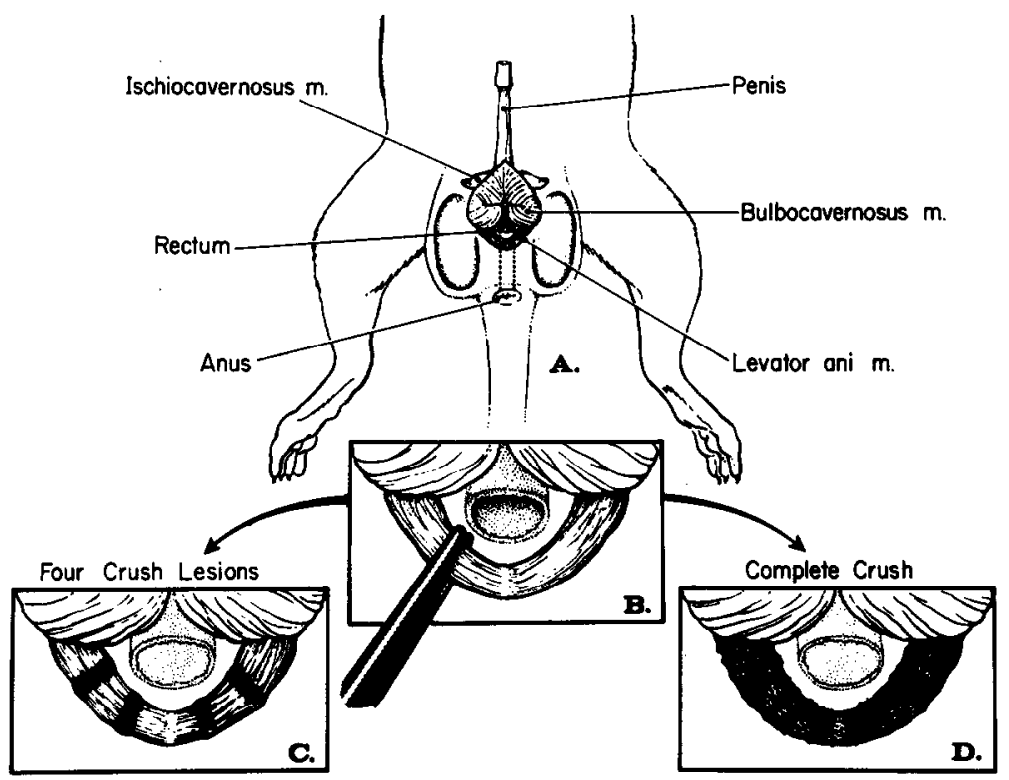

FIG. 1. Diagram illustrating the production of the crush lesions used in these experiments. A-Anatomical relationships of the levator ani muscle; $\mathrm{B}$-crushing technique; $\mathrm{C}$-levator ani, showing the location of the four crush lesions; and $\mathrm{D}$-completely crushed levator ani.

this muscle normally undergoes complete involution in female rats between the 7 th and 21 st days of postnatal life (5). In males it persists and increases in relative size at puberty.

After castration, the levator ani in male rats decreases greatly in size. This can be prevented by the administration of testosterone $(7,22)$. The changes due to castration or hormone administration take place at the level of the individual muscle fiber rather than as a result of changing the populations of muscle fibers within the muscle $(20,21)$. Involution of this muscle in female rats can be prevented by the administration of testosterone ( 5 , 9).

Physiologically, the levator ani is a fast muscle $(1,10)$. The histochemical picture confirms the contractile properties. The muscle fibers stain almost uniformly positively for myofibrillar ATPase activity whereas succinic dehydrogenase activity is uniformly low (11).

This investigation was undertaken to answer two basic questions. (i) Does the levator ani muscle in the male rat regenerate in a manner similar to the regeneration of other skeletal muscles in the rat? and (ii) Does the regenerating levator ani muscle retain or reacquire its high degree of sensitivity to testosterone? 


\section{MATERIALS AND METHODS}

This investigation was carried out on 1401 -month-old male rats. The rats used in Prague for physiological and histochemical analysis were of the Wistar strain whereas those used for descriptive and quantitative histological analysis in Ann Arbor were Sprague-Dawley rats (Charles River).

The means chosen to produce degeneration and regeneration of the levator ani muscle was mechanical crushing. The rats were all anesthetized with ether, and the levator ani was exposed through an incision made along the scrotal raphe. Two types of crush lesions were made. Initially, four equally spaced crush lesions $3 \mathrm{~mm}$ wide were made by tightly clamping the muscle with a hemostat (Fig. 1C). The four-crush model produced complete destruction of muscle fibers in the lesion, but it proved unsatisfactory for most forms of analysis of later regenerating muscles because of survival of functional segments of muscle fibers in the areas between crush lesions. For the bulk of the animals, the levator ani was completely crushed by overlapping clamping with the hemostat (Fig. 1D). This procedure was adequate for studies on contractile properties of the regenerating muscle. It was also used exclusively for the histological studies. Postoperatively, the rats were treated with penicillin or Terramycin for 4 days.

Hormonal Status of Rats. In these experiments the rats were divided into three groups with respect to hormonal status. The first group contained rats whose hormonal status was normal. In the second group the rats were castrated at the time of the muscle crushing operation. Rats in the third group received supplementary testosterone. In Prague, the rats received daily injections of $2.5 \mathrm{mg}$ testosterone propionate (Spofa)/100 $\mathrm{g}$ body weight for the duration of the experiment (physiological and histochemical groups). Hormone administration in the Ann Arbor rats was accomplished by implanting $62.5-\mathrm{mm}$ lengths of Dow-Corning Silastic tubing [0.32-cm (0.125-in.) outer diameter and 0.16-cm (0.062-in.) inner diameter] filled with testosterone propionate (U.S. Biochemical Corp.) beneath the skin of the back. This procedure results in the continuous release of $2.5 \mathrm{mg}$ hormone per day (2).

Analysis of Contractile Properties. Analysis of contractile properties was carried out on 4-, 7-, 14-, and 30-day regenerated muscles. They were removed by cutting through the bulbocavernosus muscles close to their attachment to the levator ani. Ligatures were fixed to the fragments of the bulbocavernosus muscles in order to prevent damage to the fibers of the levator ani. The muscles were placed in a $36^{\circ} \mathrm{C}$ chamber containing an oxygenated culture medium $\left(149.8 \mathrm{~mm} \mathrm{Na}^{+}, 5.0 \mathrm{mM} \mathrm{K}, 2.0 \mathrm{mM} \mathrm{Ca}^{2+}, 148.0 \mathrm{~mm}\right.$ $\mathrm{Cl}^{-}, 12.0 \mathrm{~mm} \mathrm{HCO}_{3}^{-}, 1.0 \mathrm{mM} \mathrm{H}_{2} \mathrm{PO}_{4}$, and $11.0 \mathrm{~mm}$ glucose, $p \mathrm{H} 7.2$ ) to which $0.01 \mathrm{~m}$ tubocurarine had been added. The muscles were equilibrated $10 \mathrm{~min}$ in this medium and then the optimal resting tension for isometric 


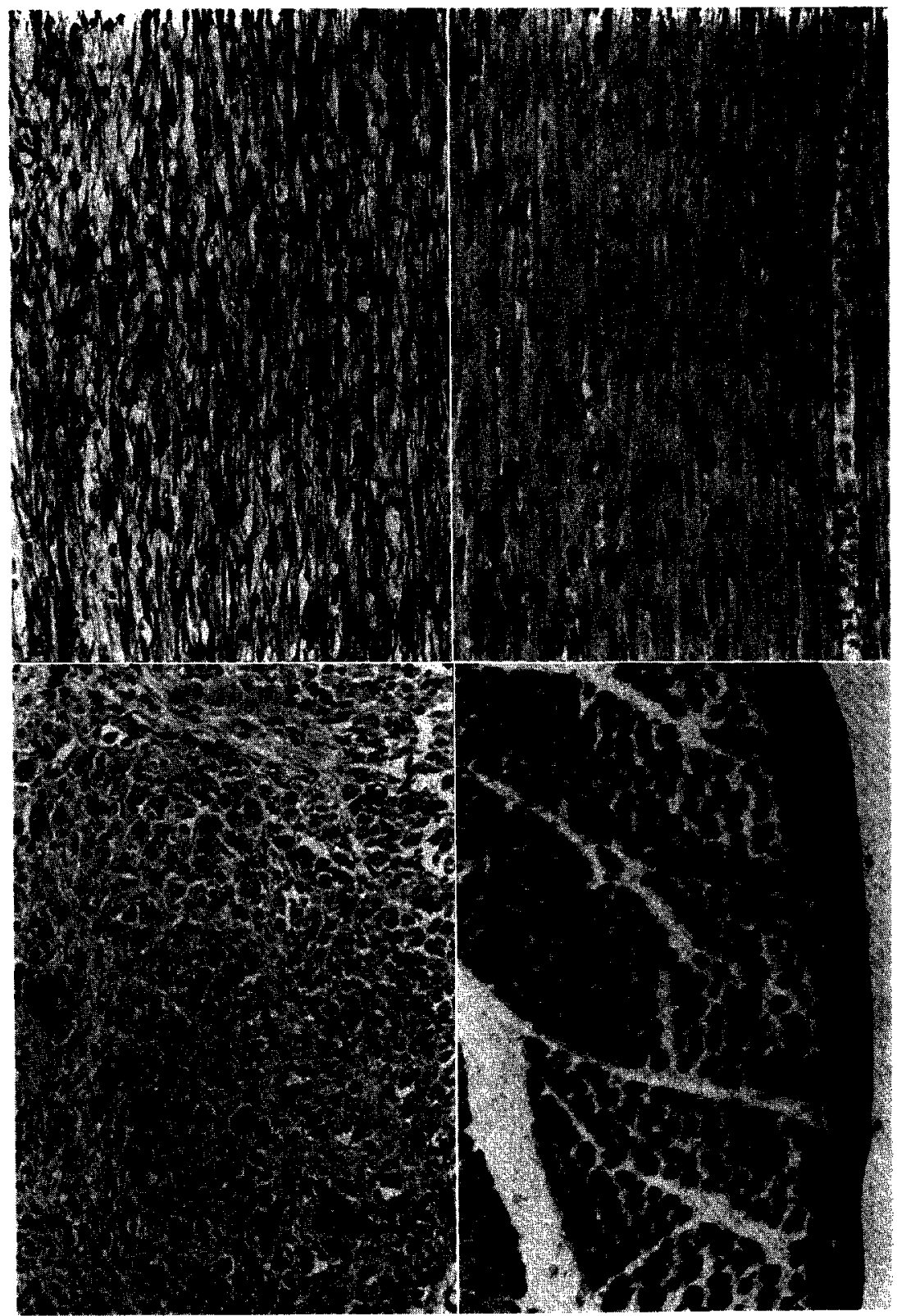

FIG. 2. Longitudinal section through the levator ani muscle 3 days after complete crushing. The original muscle fibers have broken down and spindle-shaped, presumably myoblastic cells are a major component of the tissue. Hematoxylin and eosin. $\times 190$.

FIG. 3. Longitudinal section through the levator ani muscle 7 days after complete crushing. The field is dominated by immature cross-striated muscle fibers. Hematoxylin and eosin. $\times 190$. 
recording was determined by direct stimulation of the muscles with platinum electrodes. Recordings of the following contractile properties were made: twitch and tetanic tension, latency period (stimulus artifact to first mechanical response), contraction time (time to peak tension), half-relaxation time (from peak to one-half amplitude of the twitch), and the time parameter of twitch tension development (18).

Histochenical Analysis. Histochemical analysis was also done on the muscles used for the measurement of contractile properties. The muscles were frozen in liquid nitrogen, and frozen sections were stained for phosphorylase (19), succinic dehydrogenase (15), myofibrillar ATPase $(8,16)$, and acid phosphatase $(14)$.

Histological Analysis. Regenerating levator ani muscles in normal rats were removed for histological analysis at $1-7,9,11,14,17,20,25,30$, and 32 days after crushing. Comparisons between groups of six regenerating muscles in normal, castrated, and hormone-treated rats were made at 7,14 , and 30 days after crushing. Muscles were fixed in Bouin's fluid and sectioned at $7 \mu \mathrm{m}$ in both cross and longitudinal planes. Sections were stained with Ehrlich's hematoxylin and eosin and with Palmgren's silver stain for nerve fibers. Cross sections of 30-day grafts were projected onto a wall, and from selected areas the outlines of 100 muscle fibers per section were traced on paper. The cross-sectional area of these muscle fibers was determined by planimetry.

\section{RESULTS}

Gross Weight. The weights of levator ani regenerating muscles in normal, castrated, and hormone-treated rats are given in Table 1. For the sake of consistency, the weights are compared in a standard ratio of muscle weight (milligrams) to body weight (grams). Significant differences are not seen among the groups of 7 - and 14-day regenerating muscles, but by 31 days those in castrated animals are much smaller than those in rats with normal or above-normal amounts of testosterone.

Histology. Overall, the histology of the regenerative process in normal rats resembles closely that of a typical limb muscle. For the first 2 days after crushing the damaged muscle fibers are in a phase characterized

FIG. 4. Cross section through the levator ani muscle 7 days after complete crushing. Immature muscle fibers are densely packed among areas of connective tissue. Hemaoxylin and eosin. $\times 190$.

Frg. 5. Cross section through the levator ani muscle 14 days after complete crushing. A superficial layer of connective tissue is developing on the surface of the muscle (right cdgc). The rcgencrating muscle fibcrs are increasing in diametcr and somc nuclei are moving out to a peripheral position. Hematoxylin and eosin. $\times 190$. 
TABLE 1

Effects of Castration and Testosterone Propionate on Weight of the Regenerating Levator Ani Muscle in the Rat

\begin{tabular}{|c|c|c|c|c|c|c|}
\hline \multirow{2}{*}{$\begin{array}{l}\text { Age of } \\
\text { graft } \\
\text { (days) }\end{array}$} & \multicolumn{2}{|c|}{ Normal } & \multicolumn{2}{|c|}{ Castrated } & \multicolumn{2}{|c|}{ Testosterone propionate } \\
\hline & $\begin{array}{c}\text { Wt } \\
(\mathrm{mg})\end{array}$ & $\begin{array}{c}\text { Muscle } \\
\text { wt/body wt } \\
(\mathrm{mg} \%)\end{array}$ & $\begin{array}{c}\mathrm{Wt} \\
(\mathrm{mg})\end{array}$ & $\begin{array}{c}\text { Muscle } \\
\text { wt/body wt } \\
(\mathrm{mg} \%)\end{array}$ & $\begin{array}{l}\mathrm{Wt} \\
(\mathrm{mg})\end{array}$ & $\begin{array}{c}\text { Muscle } \\
\text { wt/body wt } \\
(\mathrm{mg} \%)\end{array}$ \\
\hline 7 & $30.8 \pm 3.2^{a}$ & $23.5 \pm 2.0$ & $24.8 \perp 2.7$ & $19.3 \pm 1.9$ & $29.5 \pm 6.2$ & $23.8 \pm 2.1$ \\
\hline 14 & $63.6 \pm 2.4$ & $28.8 \pm 1.3$ & $40.0 \pm 6.1$ & $20.4 \pm 3.0$ & $59.0 \pm 10.1$ & $32.2 \pm 5.1$ \\
\hline 30 & $155.3 \pm 6.8$ & $50.5 \pm 5.0$ & $62.5 \pm 5.4$ & $2.3 .8 \pm 2.2$ & $144.4 \pm 16.1$ & $56.2 \pm 5.9$ \\
\hline
\end{tabular}

a Standard error.

mainly by degeneration and sarcoplasmic removal. By their third day most of the degenerating muscle has been removed, and mononuclear, spindleshape cells, presumably myoblasts, are prominent (Fig. 2). Although the regenerative process is not synchronous throughout the muscle, Days 4 and 5 are characterized by a predominance of myotubes. At this time nerve fibers are found among the regenerating muscle fibers. Scattered nerve fibers are also seen in earlier regenerated muscles. It is likely that these nerve fibers remained intact through the crushing of the muscle fibers.

The transition from myotubes to early cross-striated muscle fibers is completed by the end of the first week (Figs. 3 and 4). During the next week the muscle fibers gradually increase in diameter, but most of the nuclei remain in a central position (Fig. 5). The nuclei begin to shift to peripheral locations during the third and fourth weeks and in 1-month-old regenerating muscles the fibers are mature looking, with angular crosssectional outlines and peripheral nuclei (Fig. 6). The regenerating muscle fibers, however, are thinner than normal muscle fibers, and some central nuclei persist. Persisting central nuclei in varying proportions are characteristic of mature regenerating muscle, and they provide a useful marker for distinguishing regions of regenerating from normal muscle fibers.

At 7 days it is not possible to distinguish between regenerating muscles of the three groups of rats by routine histological examination. By 30 days, the difference between regenerating muscles in castrated rats and noncastrated rats is readily apparent (Figs. 6 and 7, Table 2). There is no significant difference in cross-sectional areas of regenerating muscle fibers between normal and hormone-treated rats at 30 days, but the muscle fibers in the latter group are about $20 \%$ larger than in the normal group. Although in castrated rats the muscle fibers are fairly tightly clustered at the lower end of the size range, there is a large spread in the size of fibers in regenerating muscles from both the normal and the hormone-treated groups (Fig. 8). 


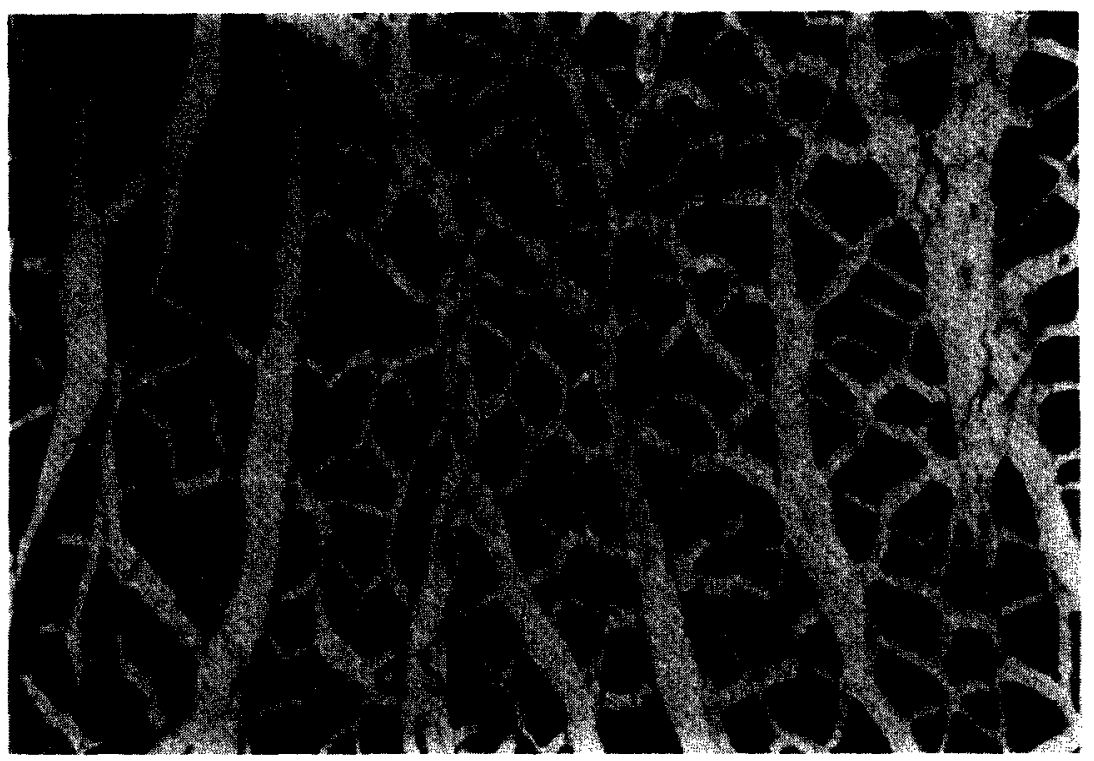

Fig. 6. Cross section through the levator ani muscle 30 days after complete crushing. The regenerating muscle fibers are becoming angular in outline and most nuclei have moved to the periphery. As is typical of regenerating muscle fibers, however, a number of nuclei remain in a central location. Hematoxylin and eosin. $\times 250$.

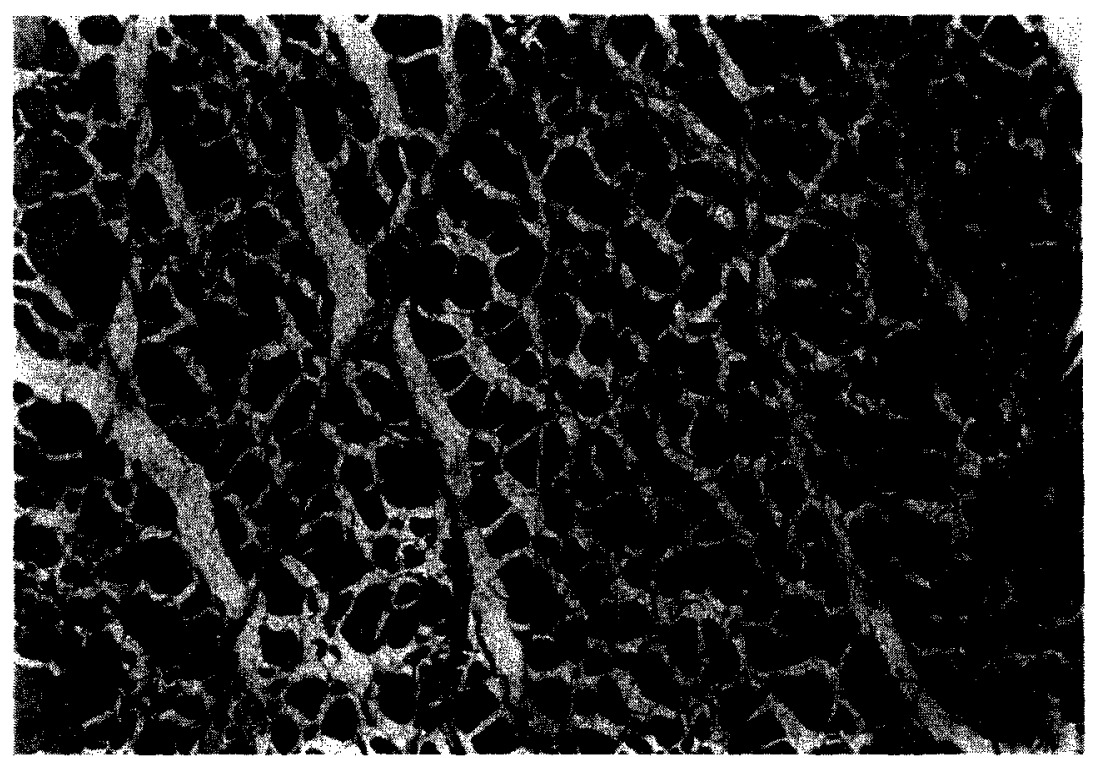

FIG. 7. Cross section through the levator ani muscle 30 days after complete crushing and simultaneous castration of the rat. The muscle fibers are much smaller than those regenerating in normal rats, and the variation in size is considerable. Hematoxylin and eosin. $\times 250$. 
TABLE 2

Mean Cross-Sectional Areas of Muscle Fibers from 30-Day Regenerating Muscles in Normal, Castrated, and 'Testosterone-Treated Rats

\begin{tabular}{lcc}
\hline & No. & $\begin{array}{c}\text { Mean cross-sectional } \\
\text { area } \pm \mathrm{SE} \\
\left(\mu \mathrm{m}^{2}\right)\end{array}$ \\
\hline Normal & 4 & $480.7 \pm 70$ \\
Castrated & 4 & $137.6 \pm 24$ \\
Testosterone-treated & 5 & $596.0 \pm 49$ \\
\hline
\end{tabular}

Contractile Properties. The normal levator ani muscle of male rats is a fast-contracting muscle (10). After a complete crush lesion, the pattern of restoration of contractile properties of the levator ani resembles that of other regenerating fast muscles $(3,4)$.

In normal rats the twitch and tetanic tensions of 4-day regenerating muscles are very weak and progressively increase as they mature (Fig. 9). The twitch-tetanus ratios decline from 0.63 at 4 days to 0.18 at 30 days. In testosterone-treated rats both twitch and tetanic tensions rise at a more rapid rate than they do in normal rats (Fig. 9), but the increase in twitch tension is not significant.

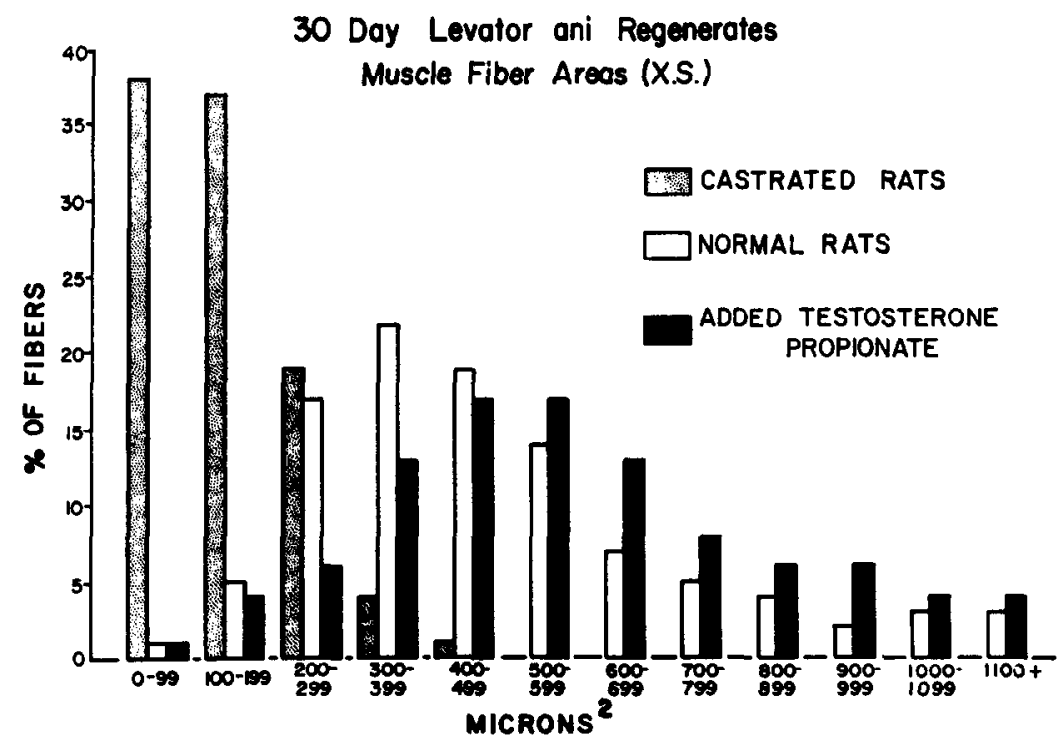

Fig. 8. Graph showing the distribution of cross-sectional areas of muscle fibers in 1-month-old regenerating levator ani muscles in normal, castrated, and hormonetreated rats. 
The contractile speeds are slow at 4 and 7 days and speed up substantially by 14 and 30 days (Table 3 ). The major differences between regenerating muscles in normal and testosterone-treated rats are found in the contraction times and half-relaxation times of 7- and 14-day regenerating muscles in which the speeds are faster in testosterone-treated rats. By 30 days these differences are no longer apparent.

Castration produces a significant slowing of contractile speeds in the regenerating levator ani (Table 4). At 14 days, when regenerating muscles in testosterone-treated rats have more rapid contraction and half-relaxation times than those in normal rats, the contraction and half-relaxation times of regenerating muscles in castrated rats are almost twice as slow as those in normal 14-day regenerating muscles.

When castrated rats are treated with daily injections of testosterone propionate, the contractile times of 14-day regenerating muscles are not significantly different from those of 14-day regenerating muscles in normal rats (Table 4).

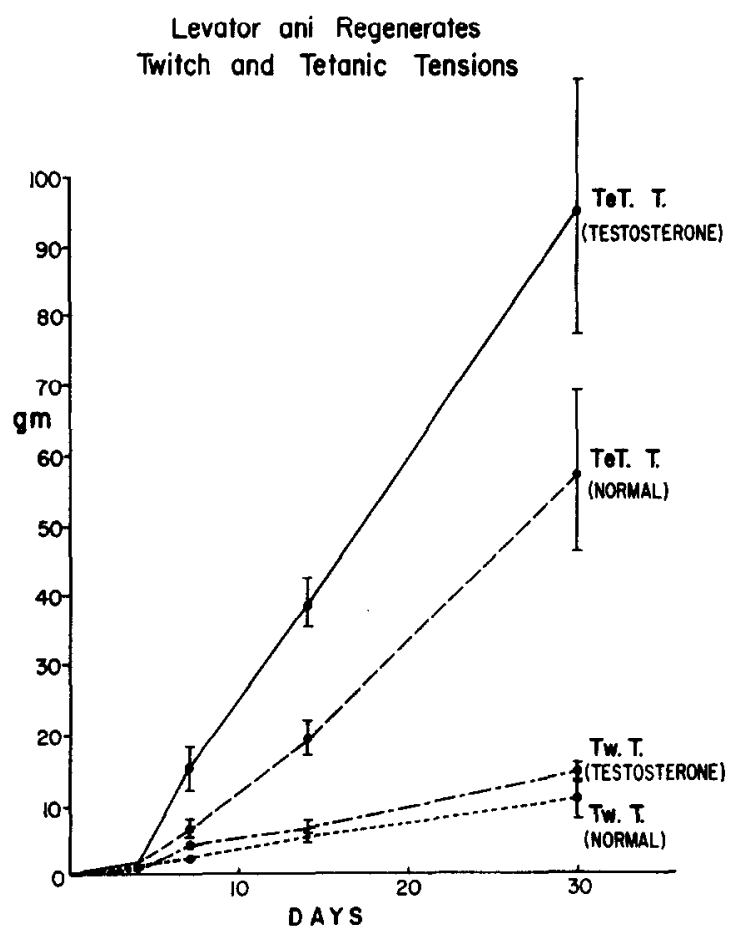

Fig. 9. Graph comparing the development of twitch and tetanic tensions of regenerating levator ani muscles measured 4 to 30 days after crushing in normal and testosterone-treated rats. Tw.T.- twitch tension; Tet.T.--tetanic tension. 


In addition to the animals with complete crush lesions, contractile properties were measured in 18 normal and 12 testosterone-treated muscles which contained four evenly spaced crush lesions. The contractile data (and later morphological examination) revealed that substantial amounts of original muscle survive and remain functional in the segments between the local crush lesions. Thus at 7 days the mean twitch tension in muscles bearing four crush lesions is $11.03 \mathrm{~g}$, in contrast to $2.40 \mathrm{~g}$ in completely crushed muscles. Early contractile speeds are uniformly more rapid in four-crush muscles than in their completely crushed counterparts. By 30 days contractile properties do not differ in muscles subjected to the two types of crushing procedures.

Histochemical Analysis. Of the means of analysis used in this experiment, histochemistry proved to be the least valuable technique. Fibers of the normal levator ani muscle are virtually homogeneous with respect to ATPase (high) and succinic dehydrogenase (low) activity.

Shortly after crushing, phosphorylase activity virtually disappears from the damaged muscle fibers. Phosphorylase activity reappears and becomes progressively greater as the regenerating muscle fibers differentiate.

In muscles with four-crush lesions, acid phosphatase activity is strikingly elevated in the region of the crush at 4 days. Activity in the regions of intact muscle between the lesions is low and little different from that seen in normal muscle.

Thirty-day regenerating muscles stain uniformly positively for ATPase activity and show uniformly low SDH activity. No differences in histochemical staining are detectable between regenerating muscles in nornal and hormone-treated rats.

\section{DISCUSSION}

For proper interpretation of these experiments one must keep in mind the age of the rats at any given point in the regenerative prucess, for these animals are undergoing pubertal changes during this period. At the time of crushing the muscle the rats were 30 days old. At this time male rats secrete minimal amounts of testosterone into the blood $(13,17)$. Concentrations of testosterone in the blood are rising in the rats during the early sampling period ( 4,7 , and 14 days), and in rats with 30 -day regenerating muscles (60 days of age) the concentration of testosterone in the blood is very high (13).

In general, the regenerating muscles were more responsive to added testosterone during the early postoperative intervals, whereas the effects of castration were more prominent in older regenerating muscles. The most pronounced effect of added testosterone was on the contraction times and half-relaxation times of 7 - and 14-day regenerating muscles, which in 
hormone-treated animals were faster than in normal rats. From our studies it has not been possible to identify a morphological basis for this difference in functional properties. On the basis of the developmental speeding of contraction time that occurs in regenerating fast muscles, one might expect that testosterone accelerated the rate of regeneration. Histological examination of normal and hormone-treated regenerating muscles at 7 and 14 days did not reveal any differences that could be defined by visual inspection, but the possibility that there are minor morphological differences in the differentiation of the regenerating muscle fibers cannot be excluded. The differences in contractile speeds were eliminated by 30 days of regeneration, at which time the rats' intrinsic hormonal environment may have reduced the impact of the added testosterone. One effect of testosterone treatment which does persist until 30 days is the increased tetanic tension generated by the regenerated muscles.

The effects of castration on the contractile properties was readily apparent 14 days after crushing, at which time the regenerating muscles contract extremely slowly in comparison with normal and hormone-treated regenerating muscles. Morphological effects of castration and differences in gross weight are not consistent in 14-day grafts. It is possible that statistically significant differences in mean cross-sectional areas of muscle fibers between regenerating muscles in normal and castrated rats exist, but because of the variability in size of muscle fibers within individual regenerating muscles at this time immense numbers of muscle fibers would have to be measured to avoid significant sampling error. By 30 days, there are obvious differences in both gross weight and cross-sectional areas of the muscle fibers between levator regenerating muscles and those of normal and castrated rats.

That the effects of castration on regeneration of the levator ani are due to a reduction in testosterone is supported by the experiment (Table 4) in which replacement therapy by testosterone resulted in the return of contractile properties in 14-day regenerating muscles to normal values. We thus conclude that the regenerating levator ani muscle in the rat, like the normal muscle, is highly sensitive to the effects of testosterone.

At this time it is not possible to state whether the levator ani muscle retains a sensitivity to testosterone at all stages of the degenerative and regenerative process following trauma or if hormonal sensitivity is lost and subsequently reacquired by the regenerating muscle cells at a certain stage of differentiation. In neither the normal nor the regenerating levator ani has it been established with certainty whether testosterone or dihydrotestosterone is the main hormone that is bound to the androgen receptors in the muscle $(6,12)$. 
Except for its sensitivity to testosterone, the process of regencration of the levator ani muscle does not appear to differ in any substantial way from the regeneration of typical fast muscles in the limb. Limb muscles do not respond to an increase in tesosterone. After daily injections of testosterone propionate, soleus muscles regenerating in situ 7 days after complete crushing did not differ from 7 -day regenerating soleus muscles in any of the standard battery of contractile properties that is measured in this laboratory (Gutmann and Carlson, unpublished data).

The levator ani muscle appears to be the muscle of choice for studying the effects of androgenic steroid hormones on striated muscles in the rat. Further work remains to define the factors responsible for the acquisition and maintenance of hormonal sensitivity during the normal development and regeneration of this muscle.

\section{REFERENCES}

Bass, A., E. Gutmann, V. Hanziliková, I. Hájek, and I. Syrovy. 1969. The effect of castration and denervation upon the contraction properties and metabolism of the levator ani muscle of the rat. Physiol. Bohemoslav. 18: 177194.

2. Berndtson, W. E., C. Desjardins, And L. L. Ewing. 1974. Inhibition and maintenance of spermatogenesis in rats implanted with polydimethylsiloxane capsules containing various androgens. J. Endocrinol. 62: 125-135.

3. Carlson, B. M., ANd E. Gutmann. 1972. Development of contractile properties of minced muscle regenerates in the rat. Exp. Neurol. 36: 239-249.

4. Carlson, B. M., and E. Gutmann. 1976. Free grafting of the extensor digitorum longus muscle in the rat after Marcaine prctrcatment. Exp. Neurol. $53: 82-93$.

5. Čihak, R., E. Gutmann, and Hanzliková. 1970. Involution and hormoneinduced persistence of the M. sphincter (levator) ani in female rats. J. Anat. 106 : 93-110.

6. Dubé, J. Y., R. Lesage, and R. R. Tremblay. 1976. Androgen and estrogen binding in rat skeletal and perineal muscles. Can. J. Biochem. 54: 50-55.

7. Eisenberg, E., ANd G. S. Gordan. 1950. The levator ani muscle of the rat as an index of myotrophic activity. J. Pharmacol. Exp. Ther. 99: 38-44.

8. Guth, L., and F. J. Samaha. 1970. Procedure for the histochemical demonstration of actimyosin ATPase. Exp. Neurol. $28: 365-367$.

9. Gutmann, E., V. Hanzlikoví and R. Ċihak. 1967. Presistence of the levator ani muscle in female rats. Expcrientia $23: 852$.

10. Hanzliková, V., and E. Gutmann. 1972. Effect of foreign innervation on the androgen-sensitive levator ani muscle of the rat. Z. Zellforsch. 135: 165-174.

11. Hanzliková, V., S. Schiaffino, and P. Settembrine. 1970. Histochemical fiber type characteristics in the normal and the persistent levator ani muscle of the rat. Histochemic 22 : 45-50.

12. Jung, I., And E. E. Bauliet. 1972. Testosterone cytosol "receptor" in the rat levator ani muscle. Nature (London) New Biol. $237: 24-26$.

13. Knorr, D. W, T. Vanha-Pertudua, and M. B. Lipsett. 1970. Structure and function of rat testis through pubescence. Endocrinology 86: 1298-1304. 
14. Lojpa, Z., and E. Gurmann. 1976. Histochemistry of sume acid hydrolases in striated muscles of the rat. Histochemistry $49: 337-342$.

15. Nachlas, M. M., K. C. Trou, E. Souza, C. S. Cheng, and A. M. Seligman. 1957. Cytochemical demonstration of succinic dehydrogenase by the use of a new p-nitrophenyl substituted ditetrazole. J. Histochem. Cytochem. 5: 420-436.

16. Padykula, H. S., and E. Herman. 1955. The specificity of the histochemical method for adenosine triphosphate. J. Histochem. Cytochem. 3: 170-195.

17. Resko, J. A., H. H. Feder, And R. W. Gov. 1968. Androgen concentratioins in plasma and testis of developing rats. J. Endrocrinol. 40 : 485-491.

18. Rohličex, V., and E. Gutmann. 1972. The constant of contraction time, a new expression of maximal rate of tension development. Physiol. Bohemoslav. $21: 430-431$.

19. Takeuchi, T., and H. Kuriaki. 1955. Histochemical detection of phosphorylase in animal tissues. J. Histochem. Cytochem. $4: 153-161$.

20. Venable, J. H. 1966. Morphology of the cells of normal, testosterone-deprived and testosterone-stimulated levator ani muscles. Am. J. Anat. 119: 271-302.

21. Venable, J. H. 1966. Constant cell populations in normal, testosterone-deprived and testosterone-stimulated levator ani muscles Am. J. Anat. 119: 263-270.

22. Wainmann, P., and G. C. Shipounoff. 1941. The effects of castration and testosterone propionate on the striated perineal musculature in the rat. Endocrinology 29 : 975-978. 